\title{
KAMPANYE GIZI SEIMBANG MELALUI KESENIAN RABAB
}

\author{
John Amos, Irma Eva Yani, Defriani Dwiyanti \\ Jurusan Gizi Poltekkes Kemenkes Padang, email
}

\begin{abstract}
The prevalence of children under five in Indonesia is still high, compared to Indonesia's MDG target of $18.5 \%$. West Sumatra is still below the target. Health problems can not only be resolved by the government, but community involvement is needed, therefore the potential needs to be mobilized. Rabab is a traditional Minangkabau traditional musical instrument made from coconut shells. This rabab can channel one's musical talents. Research with a qualitative approach to the research strategy "Case Study (CSR)" with descriptive case studies. The study is planned to be conducted on 10 (ten) rabab players active in Balai Tuesday, Pesisir Selatan Regency. Most informants stated that the message of balanced nutrition can be compiled into a story through Rabab, almost all informants stated that the message of balanced nutrition can be arranged according to the language of the local community, most informants stated that the message of balanced nutrition can be arranged in accordance with the Dialeg community, Rabab as art regions that have the potential of Minangkabau have the potential to campaign for balanced nutrition in achieving optimal health for children under five years and families. It is recommended to review the message of balanced nutrition for various ages of society through Rabab's art, to examine the influence of Rabab's art intervention on the knowledge, attitudes and actions of people of all ages in balanced nutrition
\end{abstract}

Keywords: nutrition, rabab

\begin{abstract}
Abstrak
Prevalensi anak balita di Indonesia masih tinggi, dibandingkan target MDG Indonesia 18,5\%. Sumatera Barat masih di bawah target. Masalah kesehatan tidak hanya dapat diselesaikan oleh pemerintah, tetapi keterlibatan masyarakat diperlukan, oleh karena itu potensi perlu dimobilisasi. Rabab adalah alat musik tradisional Minangkabau tradisional yang terbuat dari batok kelapa. Dengan rabab ini bisa menyalurkan talenta bermusik seseorang. Penelitian dengan pendekatan kualitatif dengan strategi penelitian "Studi Studi Kasus (CSR)" dengan studi kasus deskriptif. Studi ini direncanakan akan dilakukan pada 10 (sepuluh) pemain rabab yang aktif di Balai Selasa, Kabupaten Pesisir Selatan. Sebagian besar informan menyatakan bahwa pesan gizi seimbang dapat disusun menjadi cerita melalui Rabab, hampir semua informan menyatakan bahwa pesan gizi seimbang dapat disusun sesuai dengan bahasa masyarakat setempat, sebagian besar informan menyatakan bahwa pesan gizi seimbang dapat disusun sesuai dengan masyarakat dialeg minang, Rabab sebagai seni daerah yang memiliki potensi Minangkabau memiliki potensi untuk mengkampanyekan gizi seimbang dalam mencapai kesehatan optimal untuk anak di bawah lima tahun dan keluarga. Dianjurkan untuk meninjau pesan nutrisi seimbang untuk berbagai usia masyarakat melalui seni Rabab, untuk menguji pengaruh intervensi seni Rabab pada pengetahuan, sikap dan tindakan orang-orang dari segala usia pada nutrisi seimbang.
\end{abstract}

Kata Kunci : Nutrisi, Rabab

Penerbit: Poltekkes Kemenkes Padang, http://jurnal.poltekkespadang.ac.id/ojs/index.php/jsm 


\section{PENDAHULUAN}

Prevalensi balita yang mengalami gizi kurang di Indonesia masih tinggi. Berdasarkan data Riskesdas 2013 prevalensi gizi kurang 19,6\%. Sedangkan untuk Sumatera Barat untuk tahun 2007 (20,2\%), 2010 (17\%) dan 2013 (21\%). Jika dibandingkan target MDGs untuk Indonesia sebesar 18,5\% Sumatera Barat masih berada dibawah target tersebut. Munculnya masalah gizi ini salah satu penyebabnya dapat disebabkan karena pola asuh makan yang tidak benar dimana keinginan makan anak selalu tergantung makanan yang dibuat dari makanan pabrik, sementara makanan berbahan lokal sngat sedikit disosialisasikan. Untuk menciptakan makanan berbasis bahan lokal perlu disosialisasikan dengan berbagai upaya atau cara. Gizi seimbang adalah susunan makanan sehari-hari yang mengandung zat -zat gizi dalam jenis dan jumlah yang sesuai dengan kebutuhan tubuh, dengan memperhatikan prinsip keanekaragaman atau variasi makanan, aktivitas fisik, kebersihan, dan berat badan (BB) ideal. Prinsip Gizi Seimbang divisualisasi sesuai dengan budaya dan pola makan setempat. Di Indonesia dalam bentuk tumpeng dengan nampannya yang untuk selanjutnya akan disebut sebagai “Tumpeng Gizi Seimbang” (TGS).

Masalah kesehatan tidak hanya bisa diselesaikan oleh pemerintah, tapi yang tidak kalah pentingnya adalah keterlibatan masyarakat. Untuk itu, potensi yang dimiliki masyarakat perlu digerakkan. Potensi tersebut antara lain adalah pengetahuan tradisional yang berakar dari budaya lokal yang berkembang di masyarakat. Pemberdayaan masyarakat berbasis pada masyarakat dapat diartikan bahwa pembangunan kesehatan berbasis pada tata nilai perorangan, keluarga dan masyarakat sesuai dengan keragaman sosial budaya, kebutuhan permasalahan, serta potensi masyarakat (modal sosial) (Depkes RI, 2009).

Strategi pemberdayaan masyarakat merupakan salah satu pendekatan pembangunan yang berpusat pada rakyat, yang berupaya keras untuk mencapai kebutuhan strategis masyarakat secara tidak langsung melalui kebutuhan praksis masyarakat. Pemberdayaan masyarakat tidak hanya berkaitan dengan pengembangan potensi ekonomi rakyat, tetapi juga peningkatan harkat dan martabat, rasa percaya diri dan harga dirinya, serta terpeliharanya tatanan nilai budaya lokal. Pemberdayaan sebagai konsep sosial budaya yang implementatif tidak hanya bertujuan menumbuh-kembangkan nilai tambah ekonomis, tetapi juga nilai tambah sosial budaya.

Setiap kelompok masyarakat dengan berbagai lingkungan fisik, sosial budaya yang majemuk di Indonesia pasti memiliki kearifan-kearifan lokal. Kearifan lokal tersebut terdapat hampir di semua wilayah baik pedesaan maupun perkotaan. Kearifan lokal ini dapat dimanfaatkan untuk mendorong keberhasilan program perbaikan gizi terutama peningkatan 
perilaku masyarakat setempat. Selama ini banyak potensi lokal yang sudah tumbuh dan berkembang secara turun temurun kurang dimanfaatkan sebagai sumber daya dalam program perbaikan gizi masyarakat. Untuk itu, upaya untuk menggali dan membangkitkan, dan mengaktualisasikan potensi lokal yang ada ada di masyarakat kemudian diubah menjadi gagasan-gagasan strategis sebagai bagian yang terpenting dalam program perbaikan gizi masyarakat.

Sistem sosial budaya yang beraneka ragam harus dipahami dan disadari sebagai sumber daya atau modal sosial (social capital) yang telah tersedia di masyarakat. Walaupun di beberapa daerah, sistem sosial budaya tersebut telah mengalami pergeseran dan mulai memudar, namun jika hal ini dimobilisasi kembali dengan cara-cara yang tepat dan sesuai dengan karakteristik sosial-budaya lokal secara bertahap akan memberikan kontribusi yang signifikan dalam pembangunan kesehatan khususnya dalam upaya mengurangi kurang gizi pada ibu dan balita (Hikmat, 2010).

Perilaku masyarakat khususnya masyarakat tradisional tercermin dari perilaku mereka dalam memanfaatkan kearifan lokal berupa pengetahuan tradisional dan keanekaragaman hayati di lingkungannya. Praktek budaya terkait kesehatan tersebut, sebagian diklaim oleh orang-orang dengan pengetahuan "modern" sebagai salah satu penyebab buruknya status kesehatan masyarakat setempat.

Rabab adalah alat musik gesek tradisional khas Minangkabau yang terbuat dari tempurung kelapa. Dengan rabab ini dapat tersalurkan bakat musik seseorang. Biasanya dalam rabab ini dikisahkan berbagai cerita nagari atau dikenal dengan istilah Kaba. Kesenian Rabab sebagai salah satu kesenian tradisional yang tumbuh dan berkembang dalam kebudayaan masyarakat Minangkabau, tersebar dibeberapa daerah dengan wilayah dan komunitas masyarakat yang memiliki jenis dan spesifikasi tertentu. Rabab Darek, Rabab Piaman dan Rabab Pasisie merupakan salah satu kesenian tradisional yang cukup berkembang dengan wilayah dan di dukung oleh masyarakat setempat. Rabab Darek tumbuh dan berkembang di daerah darek Minangkabau meliputi Luhak nan Tigo sedangkan Rabab Piaman berkembang di daerah pesisir barat Minangkabau, yang meliputi daerah tepian pantai (pesisir). Penelitian ini ingin melihat apakah rabab sebagai kesenian yang bersifat kerakyatan daerah Minangkabau mempunyai berpotensi untuk mengkampanyekan gizi seimbang untuk mencapai sehat optimal bagi anak balita dan keluarga. 


\section{METODE PENELITIAN}

\section{Pendekatan/Stategi Penelitian}

Penelitian ini merupakan penelitian lapangan yang berbentuk deskriptif-interpretatif, yang menggunakan metode penelitian kualitatif. (Cresswell, 2009:5).

\section{Lokasi Dan Waktu Penelitian}

Penelitian ini direncanakan dilaksanakan di Kec Balai Selasa Kabupaten Pesisir Selatan pada pemain rabab dan ibu balita penonton rabab tersebut pada bulan Maret sampai dengan Nopember 2015.

\section{Informan Penelitian}

Informan penelitian terdiri dari pemain rabab dan ibu balita penonton rabab. Sedangkan teknik pengambilan informan penelitian adalah menggunakan non probability sampling (Sugiyono, 2005) yaitu purposive sampling pada pemain rabab 10 (sepuluh) orang dan 30 (tiga puluh) orang ibu balita yang pernah menonton rabab.

\section{Pengumpulan Data}

Data atau informasi yang dikumpulkan terdiri dari data primer dan data sekunder. Pengumpulan data primer dilakukan dengan diskusi kelompok terarah (focus group discussion/FGD, dan wawancara mendalam (indepth interview).

\section{Pengolahan dan Analisa Data}

Pengolahan data dilakukan secara komputerisasi dan dianalisis secara diskriptif.

\section{HASIL DAN PEMBAHASAN}

\section{Pesan Gizi Seimbang Disusun Menjadi Cerita Yang mudah Dimengerti Melalui Rabab}

Sebagian besar informan menyatakan bahwa pesan gizi seimbang dapat disusun menjadi cerita melalui rabab, melalui hal-hal yang berhubungan dengan kehidupan seharihari atau fenomena-fenomena yang terjadi pada masyarakat dan informasi gizi yang yang diceritakan hal-hal penting dan alur ceritanya yang bagus.

\section{Pesan Gizi Seimbang Disusun Sesuai Bahasa Masyarakat Setempat}

Hampir seluruh informan menyatakan, bahwa pesan gizi seimbang dapat disusun sesuai bahasa masyarakat setempat, yaitu dengan mengubah kata-kata yang ada dengan 
bahasa yang mudah dimengerti ("bahasa minang"), karena karena hanya merubah bahasa Indonesia ke bahasa minang bukanlah soal yang susah di saat sekarang ini.

\section{Pesan Gizi Seimbang Disusun Menurut Dialeg Masyarakat Setempat}

Sebagian besar informan menyatakan bahwa pesan gizi seimbang dapat disusun menurut dialeg masyarakat minang, karena "logat minang" tidak terlalu susah dimengerti dibanding bahasa-bahasa daerah lain seperti bahasa Jawa, Sunda. Orang-orang yang menonton rabab dengan pesan gizi seimbang akan lebih tertarik mendengarkannya dibandingkan dengan menyampaikannya secara biasa.

Gambar 1. Beberapa suasana informan perabab memainkan kalimat pantun
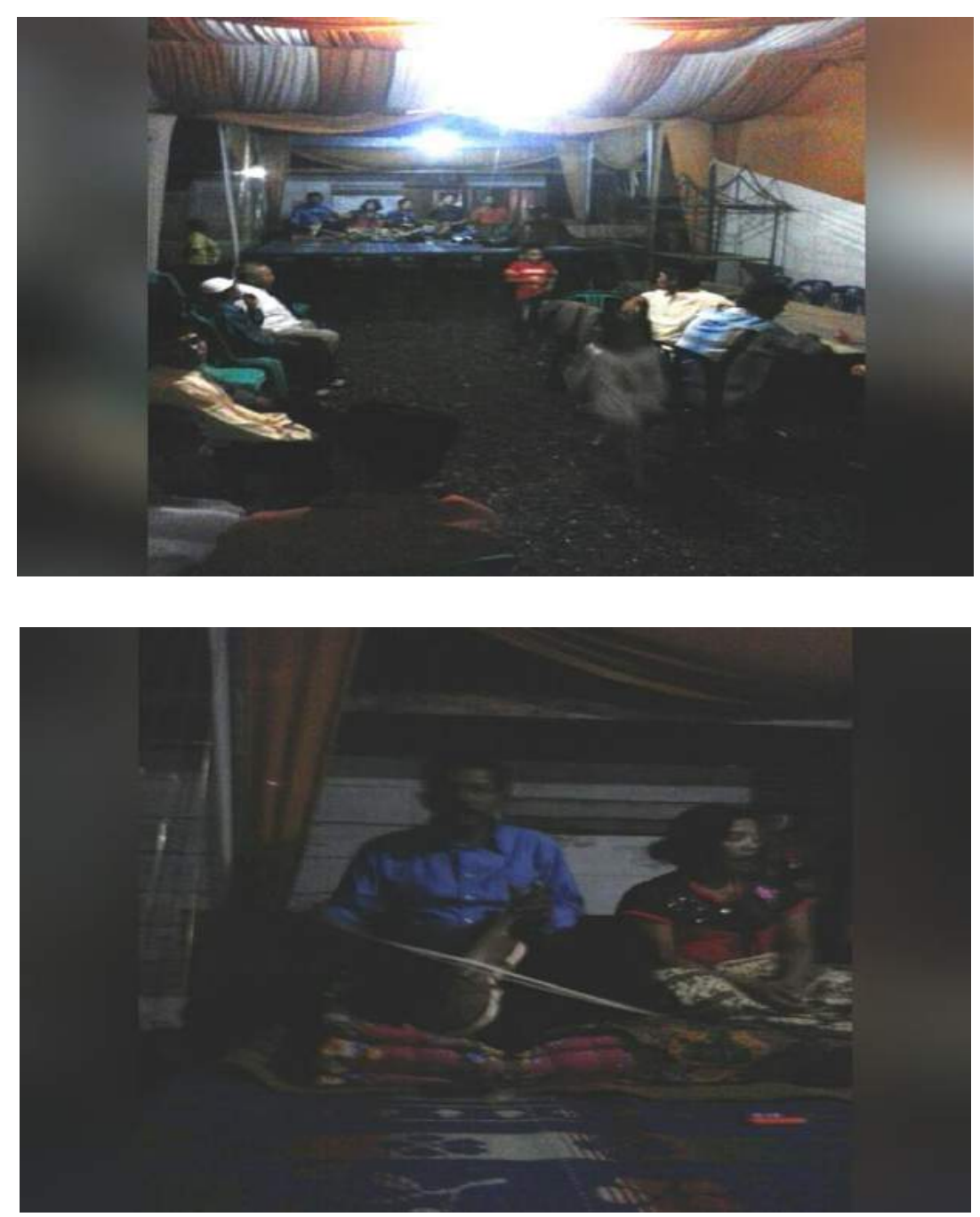


\section{KESIMPULAN DAN SARAN}

\section{Kesimpulan}

- Sebagian besar informan menyatakan bahwa pesan gizi seimbang dapat disusun menjadi cerita melalui rabab, melalui hal-hal yang berhubungan dengan kehidupan sehari-hari atau fenomena-fenomena yang terjadi pada masyarakat dan informasi gizi yang yang diceritakan hal-hal penting dan alur ceritanya yang bagus. Hampir seluruh informan menyatakan, bahwa pesan gizi seimbang dapat disusun sesuai bahasa masyarakat setempat, yaitu dengan mengubah kata-kata yang ada dengan bahasa yang mudah dimengerti ("bahasa minang"), karena karena hanya merubah bahasa Indonesia ke bahasa minang bukanlah soal yang susah di saat sekarang ini. Sebagian besar informan menyatakan bahwa pesan gizi seimbang dapat disusun menurut dialeg masyarakat minang, karena "logat minang" tidak terlalu susah dimengerti dibanding bahasa-bahasa daerah lain seperti bahasa Jawa, Sunda. Orang-orang yang menonton rabab dengan pesan gizi seimbang akan lebih tertarik mendengarkannya dibandingkan dengan menyampaikannya secara biasa. Sebagian besar informan menyatakan bahwa pesan gizi seimbang dapat disusun dengan cara meringkas informasi dalam bentuk sederhana sehingga penonton mudah memahaminya, disamping itu melalui dendang dengan memberikan sedikit lelucon maka informasi ini akan lebih menarik untuk didengar.

- Rabab sebagai kesenian yang bersifat kerakyatan daerah Minangkabau mempunyai dapat dijadikan metode mengkampanyekan gizi seimbang dalam mencapai sehat optimal bagi anak balita dan keluarga.

\section{Saran}

- Melakukan kajian terhadap pesan-pesan gizi seimbang untuk berbagai umur pada masyarakat melalui kesenian Rabab dan pengaruhnya terhadap pengetahuan, sikap dan tindakan masyarakat dengan berbagai umur tentang gizi seimbang.

- Merumuskan strategi pengembangan kesenian Rabab melalui penyusunan skenario untuk perubahan perilaku masyarakat tentang gizi seimbang. 


\section{DAFTAR PUSTAKA}

Alo, L. (2007) Dasar-Dasar Komunikasi Kesehatan. Yogyakarta. Pustaka Pelajar. Arief, S. (2002) Media Pendidikan. Jakarta. Raja Grafindo Persada.

Azhar, A. (2002) Media Pembelajaran. Jakarta. Raja Grafindo Persada.

Depkes RI. Pusat Promosi Kesehatan. (2002). Modul Dasar Kesehatan Ahli. Jakarta.

S.Karo-Karo. (1978). Penyuluhan Kesehatan Masyarakat. Diklat AKZI.

Soekidjo,N. (2003). Pendidikan dan Perilaku Kesehatan. Jakarta. Rineka Cipta.

Soekidjo,N. (2005). Promosi Kesehatan. Jakarta. Rineka Cipta.

www.yahoo.com: http://id.wikipedia.org/wiki/Rabab

www.yahoo.com:http://melayuonline.com/eng/culture/dig/2627/bakaba-the-

minangkabau- or.

Suryadi, Seni Verbal Tradisional Minangkabau di Era Komunikasi Elektronik: Media Baru, Tempat Baru, http://workshop.blhatley.id.au/summaries/suryadi\%20summary. 